\title{
The Extraretinal Eyelet of Drosophila: Development, Ultrastructure, and Putative Circadian Function
}

\author{
Charlotte Helfrich-Förster, ${ }^{1,2}$ Tara Edwards, ${ }^{3}$ Kouji Yasuyama, ${ }^{4}$ Barbara Wisotzki, ${ }^{2}$ Stephan Schneuwly, ${ }^{2}$ \\ Ralf Stanewsky, ${ }^{2}$ lan A. Meinertzhagen, ${ }^{3}$ and Alois Hofbauer ${ }^{2}$ \\ 1Zoological Institute/Animal Physiology, University of Tübingen, D-72076 Tübingen, Germany, ${ }^{2 Z}$ Zoological Institute, \\ University of Regensburg, D-93040 Regensburg, Germany, ${ }^{3}$ Life Sciences Centre, Dalhousie University, Halifax, \\ Nova Scotia, Canada B3H 4J1, and ${ }^{4}$ Department of Biology, Kawasaki Medical School, Kurashiki City, Okayama, \\ 701-0192, Japan
}

\begin{abstract}
Circadian rhythms can be entrained by light to follow the daily solar cycle. In Drosophila melanogaster a pair of extraretinal eyelets expressing immunoreactivity to Rhodopsin 6 each contains four photoreceptors located beneath the posterior margin of the compound eye. Their axons project to the region of the pacemaker center in the brain with a trajectory resembling that of Bolwig's organ, the visual organ of the larva. A lacZ reporter line driven by an upstream fragment of the developmental gap gene Krüppel is a specific enhancer element for Bolwig's organ. Expression of immunoreactivity to the product of lac $Z$ in Bolwig's organ persists through pupal metamorphosis and survives in the adult eyelet. We thus demonstrate that eyelet derives from the 12 photoreceptors of Bolwig's organ, which entrain circadian rhythmicity in the larva. Double labeling with anti-pigment-dispersing hormone shows that the terminals of Bolwig's nerve differentiate during metamorphosis in close temporal and spatial relationship to the ventral lateral neurons
\end{abstract}

$\left(\mathrm{LN}_{\mathrm{v}}\right)$, which are essential to express circadian rhythmicity in the adult. Bolwig's organ also expresses immunoreactivity to Rhodopsin 6, which thus continues in eyelet. We compared action spectra of entrainment in different fly strains: in flies lacking compound eyes but retaining eyelet $\left(\mathrm{so}^{1}\right)$, lacking both compound eyes and eyelet $\left(\mathrm{So}^{1} ; \mathrm{gl}^{60 j}\right)$, and retaining eyelet but lacking compound eyes as well as cryptochrome $\left(\mathrm{so}^{1} ; \mathrm{cry}^{b}\right)$. Responses to phase shifts suggest that, in the absence of compound eyes, eyelet together with cryptochrome mainly mediates phase delays. Thus a functional role in circadian entrainment first found in Bolwig's organ in the larva is retained in eyelet, the adult remnant of Bolwig's organ, even in the face of metamorphic restructuring.

Key words: Drosophila melanogaster; circadian rhythm; Bolwig's organ; extraretinal photoreceptors; compound eye; insect; rhodopsin
Animals possess two different types of photosensory organs. Most conspicuous are the ocular photoreceptors that provide input to organized neural networks analyzing the spatiotemporal structure of the visual world. Less obvious, extraocular photoreceptors lack this capacity for complex image analysis but often are implicated in the entrainment of circadian rhythms and the timing of photoperiodic responses. The existence of such extraocular pho-

Received Nov. 1, 2001; revised July 8, 2002; accepted Aug. 13, 2002.

This work was supported by grants from the Deutsche Forschungsgemeinschaft to C.H.-F. (Fo 207/7-1) and A.H. (Ho 798/5), to I.A.M. from Medical Research Council (MOP-36453) and the National Institutes of Health (EY-03592), and to K.Y. from the Japanese Ministry of Education, Science, Sports, and Culture $(12640668,11168233)$. We thank Drs. Steven Britt (Denver, CO) for the Rh6-TAU line, Francois Rouyer for the BS23 (Kr-BO-lacZ) line, and Karl-Friedrich Fischbach for the UAS-gfp strain. We are grateful to Drs. Heiner Dircksen (Bonn, Germany) for the PDH antiserum, Steven Britt for the Rh6 antibody, and Seymour Benzer for antibody 24B10. The monoclonal antibody 40-1a developed by Dr. Josh Sanes (St. Louis, MO) was obtained from the Developmental Studies Hybridoma Bank maintained by the University of Iowa. We thank Dr. Wolf Frommer for the use of the confocal microscope, Drs. Hans Erkert and Rüdiger Hampp for providing the laboratory facilities and climate chambers, Gesa Thies and Ilse Gräf for excellent assistance with ultrastructural and behavioral studies, and Dr. Mark von Campenhausen for extensive help with calibrating the radiometer and measuring the transmittances of the interference filters. We also thank Drs. Russell Foster and Rob Lucas for discussions and for their efforts to fit nomograms of rhodopsins and cryptochrome to our action spectra. Finally, we thank Dr. Wolfgang Engelmann for comments on this manuscript.

Correspondence should be addressed to Alois Hofbauer, Institute of Zoology, University of Regensburg, Universitaetsstrasse 31, D-93053 Regensburg, Germany. E-mail: alois.hofbauer@biologie.uni-regensburg.de.

Copyright () 2002 Society for Neuroscience 0270-6474/02/229255-12\$15.00/0 toreceptors has been established in many invertebrate and vertebrate species (Adler, 1976; Truman, 1976; Bennett, 1979; Page, 1982; Underwood and Groos, 1982). In mammals both types of photoreceptors (those for form vision and those for entraining circadian rhythms) are located within the eye but have different retinal locations and project to different centers in the brain (Morin, 1994; Freedman et al., 1999; Berson et al., 2002; Hattar et al., 2002; Provencio et al., 2002).

In insects the putative cerebral extraocular photoreceptors (Schulz et al., 1984; Hagberg, 1986; Seifert et al., 1987; Fleissner et al., 1993; Felisberti et al., 1997) lie close to, but separate from, the compound eye and optic lobe. Instead of projecting to the visual centers in the protocerebrum, they innervate the small accessory medulla, which houses the circadian pacemaker center controlling behavioral and retinal rhythms in some insects (for review, see Helfrich-Förster et al., 1998). In the fruit fly Drosophila melanogaster an extraretinal photoreceptor cluster discovered beneath the retina at the posterior margin of the compound eye projects directly to the region of the accessory medulla (Hofbauer and Buchner, 1989). This Hofbauer-Buchner (H-B) "eyelet" contains cells with pigment granules and numerous microvilli arranged in rhabdomeres, both structurally diagnostic of photoreceptors, and the rhabdomeres exhibit immunoreactivity to Rhodopsin 6 (Rh6) (Yasuyama and Meinertzhagen, 1999), suggesting that the photoreceptors are functional. Like the photoreceptors of the retina, eyelet is immunoreactive to histamine 
(Pollack and Hofbauer, 1991). Although eyelet appears well suited to transfer information about day and night to the circadian pacemaker center, direct proof for this role is still lacking. Drosophila uses several light input pathways for circadian entrainment: one through the blue-light photopigment cryptochrome, another through the compound eyes/ocelli, and an extraocular pathway possibly involving eyelet (Helfrich-Förster et al., 2001). Given this redundancy, it is difficult to assign the functional role of eyelet in the presence of the other photoreceptors.

Little is known about the origin and development of eyelet. Whereas the adult fly has no fewer than seven eyes (Hofbauer and Buchner, 1989), the fly's larva has but one described organ of sight, Bolwig's organ (Bolwig, 1946), a bilateral cluster of 12 photoreceptors in the larval mouthhooks (Steller et al., 1987; Hofbauer and Campos-Ortega, 1990). These are a possible larval precursor of eyelet (Yasuyama and Meinertzhagen, 1999), the axons of which mimic the larval path of Bolwig's nerve after the adult optic neuropils form (Meinertzhagen and Hanson, 1993); both, moreover, are immunoreactive to choline acetyltransferase (ChAT) (Yasuyama et al., 1995; Yasuyama and Meinertzhagen, 1999). Although Bolwig's organ previously had been reported to degenerate (Tix et al., 1989), recent evidence indicates that it persists throughout metamorphosis (Gibbs and Truman, 1998).

The terminals of both eyelet (Yasuyama and Meinertzhagen, 1999) and Bolwig's organ (Kaneko et al., 1997) overlap the arborization of pigment-dispersing hormone (PDH) neurons, which are implicated in regulating behavioral and cellular circadian rhythms (Meinertzhagen and Pyza, 1996; Pyza and Meinertzhagen, 1997; Renn et al., 1999; Helfrich-Förster et al., 2000). To study the function of eyelet in detail, we therefore compared the action spectrum of eyeless flies that retain eyelet with that of eyeless flies lacking eyelet, enabling us to unmask the photopigments underlying the circadian response to light, as determined for the eclosion rhythm of D. pseudoobscura (Frank and Zimmermann, 1969; Klemm and Ninnemann, 1976), the activity rhythm of D. melanogaster (Blaschke et al., 1996; Ohata et al., 1998; Suri et al., 1998), and the degradation of the Timeless protein (Suri et al., 1998). Action spectra also uncover subtle differences in sensitivity between mutants. For example, whereas white-light pulse experiments fail to reveal sensitivity differences between wildtype and eyeless flies (Yang et al., 1998), action spectra reveal that the former are more sensitive to wavelengths $>550 \mathrm{~nm}$ (Blaschke et al., 1996; Ohata et al., 1998). Our present study suggests that eyelet plays an active role in circadian photoreception.

\section{MATERIALS AND METHODS}

Fly strains. Drosophila melanogaster line BS23 (Kr-BO-lacZ) was kindly provided by Dr. F. Rouyer (Institut Alfred Fessard, Centre National de la Recherché Scientifique, Gif-Sur-Yvette, France). The specific enhancer element driving the expression in Bolwig's organ is a $2.3 \mathrm{~kb}$ $B g l$ II-StuI DNA fragment of the Krüppel upstream region -5.8 to 3.5 [Hoch et al. (1990); see Schmucker et al. (1992) for the creation of this line]. To obtain a timed developmental series, we collected pupae raised at $23^{\circ} \mathrm{C}$ at hourly intervals after pupariation. At this temperature $24 \mathrm{hr}$ corresponds to $20 \%$ of pupal development $(\mathrm{P}+20 \%)$ (Roberts, 1998). Mutant $s o^{1}$ flies and UAS-gfp flies carrying a $\mathrm{P}\{\mathrm{UAS}-$ GFP.S65T $\}$ insert were kindly supplied by Dr. K.-F. Fischbach (University of Freiburg, Freiburg, Germany); $g l^{60 j}$ flies were obtained from the Bloomington Stock Center (Indiana University, Bloomington, IN); Rh6-TAU flies (y w; $\mathrm{P}\left\{\mathrm{Rh} 6 \mathrm{p}\right.$-tau:lac $\left.Z, \mathrm{y}^{+}\right\}$on III) were a gift from Dr. S. Britt (University of Colorado, Denver, CO). This line expresses a TAU:lacZ marker (Callahan and Thomas, 1994) under control of the Rh6 promotor (S. Britt, personal communication). A glass multiple reporter ( $g m r)$ line expressing GAL4 (Freeman, 1996) was used together with the UAS-gfp to label photoreceptor axon projections. The flies (P\{GMR-GAL4,
$\left.\mathrm{w}^{+\mathrm{mC}}\right\}$ on II) were obtained from Dr. M. Freeman (Medical Research Council Laboratory of Molecular Biology, Cambridge, UK). Canton $S$ was used as the wild-type strain and, in addition, Oregon $R$. Mutant $s o^{I}$ flies lack ocelli and compound eyes but retain eyelet (Hofbauer and Buchner, 1989). The penetrance of the mutation is incomplete so that remnants of the compound eyes remain in some flies. We therefore chose only completely eyeless $s o^{1}$ mutants, which also have small optic lobes (Fischbach and Technau, 1984). Immunocytochemical analysis of $45 \mathrm{so}^{I}$ mutants with a photoreceptor-specific antibody (see below) revealed that both the photoreceptors of the compound eyes and the first optic neuropil, the lamina, were completely absent in all flies that were judged eyeless from external inspection. Mutations in the glass $(\mathrm{gl})$ gene, which encodes a transcription factor necessary for the general development of photoreceptors (Moses et al., 1989), impair development in all known external and internal eye structures. Flies carrying the loss-of-function allele $g l^{60 j}$ lack ocelli and all ommatidial photoreceptors plus the primary and secondary pigment cells in the compound eyes (Lindsley and Zimm, 1992; Kunes et al., 1993) as well as photoreceptors in eyelet (HelfrichFörster et al., 2001). As a consequence, they have transparent misshapen eyes. To achieve similar properties of the mutant glass $^{60 j}$ head similar to those of the $s o^{1}$ head, we generated $s o^{1} ; g l^{60 j}$ double mutants, which are eyeless like $s o^{1}$ mutants. In the double-mutant $s o^{1} ; c r y^{b}$ eyelet is retained, but the cryptochrome gene is defective (Stanewsky et al., 1998). No compound eyes or only small remnants are left.

Immunocytochemistry. To follow Krüppel expression in brains, we immediately dissected white prepupae and fixed them overnight at $4^{\circ} \mathrm{C}$ in $4 \%$ paraformaldehyde (PFA) in $0.1 \mathrm{M}$ phosphate buffer (PB), $\mathrm{pH}$ 7.4. Pupae at $\mathrm{P}+5 \%$ to $\mathrm{P}+80 \%$ were removed from the pupal case and decapitated; their heads were fixed similarly. Before $\mathrm{P}+10 \%$ the brains were processed as whole mounts. Before $\mathrm{P}+80 \%$ the decapitated heads were fixed overnight as before, washed in $0.1 \mathrm{M} \mathrm{PB}, \mathrm{pH} 7.4$, for $10 \mathrm{~min}$, and embedded in $7 \%$ agar; then $100 \mu \mathrm{m}$ Vibratome slices placed into mesh buckets were washed in $0.1 \mathrm{M}$ PB. All brains were washed $3 \times 10$ min each in $0.1 \mathrm{~PB}$ at $23^{\circ} \mathrm{C}$, followed by a 45 min wash in $0.2 \%$ Triton $\mathrm{X}-100$ (TX) in $0.01 \mathrm{~m}$ PBS, pH 7.4. They were permeabilized for $15 \mathrm{~min}$ in $2 \%$ TX in PBS, blocked in 5\% normal goat serum (NGS) in $0.2 \%$ TX-PBS for $45 \mathrm{~min}$ at $23^{\circ} \mathrm{C}$ on a shaker, and incubated for $48-72 \mathrm{hr}$ at $4^{\circ} \mathrm{C}$ in primary antibody, mouse anti- $\beta$-galactosidase $(\beta$-gal; $40-1 \mathrm{a}$, Developmental Studies Hybridoma Bank, Iowa City, IA) diluted from 1:10 to $1: 50$ in $2 \%$ NGS-TX-PBS. Brains then were washed $6 \times 10$ min each in $0.2 \% \mathrm{TX}-\mathrm{PBS}$ and incubated overnight at $4^{\circ} \mathrm{C}$ in secondary $\mathrm{Cy} 3-$ conjugated goat anti-mouse (Jackson ImmunoResearch Laboratories, West Grove, PA) diluted 1:200. Specimens were washed $3 \times 10$ min each in PBS, mounted with Vectashield (Vector Laboratories, Burlingame, CA), and imaged by laser-scanning confocal microscopy (Zeiss LSM410 or LSM510, Oberkochen, Germany). Control brains were dissected from white prepupae, and the same protocol was followed with the omission of primary antibody. The procedure at $\mathrm{P}+80 \%$ and for newly eclosed flies was the same except that the proboscis was removed first.

Immunocytochemistry for larval nervous tissue with a monoclonal antibody against the Drosophila opsin Rh6 was performed on paraffin sections by using the Vectastain avidin-biotin-peroxidase complex (ABC) method (Yasuyama et al., 1995). Isolated third instar larval cephalic complexes, including the brains and attached mouthhooks containing Bolwig's organs, were fixed in aqueous Bouin's solution, embedded in Paraplast wax, and sectioned. Sections were incubated for $45 \mathrm{hr}$ at $4^{\circ} \mathrm{C}$ with anti-Rh6 (clone 9D12) diluted 1:300. As a control, omission of the primary antibody eliminated immunolabeling of Bolwig's organ.

To test for the presence of eyelet, we dissected $s o^{1}$ and $\mathrm{gl}^{60 j}$ flies and wild-type pupae, fixed them for $3 \mathrm{hr}$ in ice-cold $4 \%$ PFA, and stored them overnight in $25 \%$ sucrose. Horizontal $10 \mu \mathrm{m}$ cryostat sections were immunolabeled with monoclonal antibody $24 \mathrm{~B} 10$ by using the $\mathrm{ABC}$ technique. This antibody directed against chaoptin selectively labels photoreceptor cells and their axonal projections (Zipursky et al., 1984). In addition, mutant $s O^{1}$ flies carrying a Rh6-TAU construct on the third chromosome were stained with anti-TAU antibody (Sigma T-5530, Deisenhofen, Germany). Some $s o^{1}$ and $g l^{60 j}$ flies were double stained as brain whole mounts with anti-chaoptin and anti-PDH as described below for wild-type brains.

Double-labeled developmental series of eyelet from whole-mount brains staged as described previously (Helfrich-Förster, 1997) were undertaken in three combinations. (1) Whole mounts were double-labeled with 24B10 (diluted 1:1000) and an antibody (diluted 1:2000) against crab PDH (Dircksen et al., 1987), which labels intensely the neurons containing Drosophila pigment-dispersing factor (PDF) (Park et al., 2000) and 
weakly some unspecific cells in the dorsal brain. Labeling was visualized with secondary fluorescence-conjugated antibodies (FITC for antichaoptin and TRITC for anti-PDH, both diluted 1:50; Jackson ImmunoResearch Laboratories). (2) We also used the GAL4/UAS system (Brand and Perrimon, 1993) to create gmr-GAL4 UAS-gfp flies in which all photoreceptors and their axon projections were labeled by green fluorescent protein, GFP. Pacemaker cells were labeled again with antiPDH and a secondary TRITC-conjugated antibody. (3) Finally, we used transgenic flies that carried the $g f p$ gene under control of the Rh6 promotor. Rh6 is expressed in a subset of R8 ommatidial photoreceptors as well as in eyelet (Yasuyama and Meinertzhagen; 1999). In all experiments the double labeling (green channel, eyelet; red channel, pacemaker cells) was visualized by laser-scanning confocal microscopy (Leica DMR, Nussloch, Germany).

Electron microscopy. Flies were fixed overnight with $4 \%$ glutaraldehyde in phosphate buffer $(0.1 \mathrm{M}, \mathrm{pH} 7.4)$ at $4^{\circ} \mathrm{C}$, postfixed with $1 \%$ osmium tetroxide in the same buffer for $1 \mathrm{hr}\left(4^{\circ} \mathrm{C}\right)$, and embedded in Durcupan. Eyelet was located in semithin sections, which were reembedded and from which thin sections then were cut and stained with lead citrate and uranyl acetate.

Behavioral analysis. Locomotor activity of individual male $s o^{1}$ and $s o^{1} ; g l^{60 j}$ flies was recorded photoelectrically as described previously (Helfrich-Förster, 1998). The monitoring device consisted of eight recording units (comprising 32 flies), which were shielded optically against each other. Halogen photo-optic lamps (Xenophot 12 V, 120 W; Osram, Berlin, Germany) equipped with Schott interference filters and a heat filter were used to illuminate each recording unit with spectral light. All interference filters had a half-width of $10 \mathrm{~nm}$; peak transmittances were $369,395,412.5,420,445,456,472,486,517,526,546,600$, and $635 \mathrm{~nm}$. Controlled via a transformer and adjusted with neutral density filters, irradiance was measured at the Max Planck Institute for Biological Cybernetics (Tübingen, Germany). Energy was measured in $\mathrm{W} / \mathrm{cm}^{2}$ with a Macam Radiometer previously calibrated by means of a precise photometer (EG \& G Radiometer/Photometer 550-1 equipped with a UV flat filter, Salem, MA). Irradiance values were converted to photons $\cdot \mathrm{cm}^{-2} \cdot \mathrm{sec}^{-1}$ by using the equation, $E=h \cdot c / \lambda$, where $E=$ photon energy, $h=$ Plank's constant $\left(6.625 \cdot 10^{-34} \mathrm{~W} \cdot \sec ^{2}\right)$, and $c=$ speed of light in vacuo, $3 \cdot 10^{17} \mathrm{~nm} / \mathrm{sec}$. Wild-type flies (Canton $S$ ) were recorded for comparison under red light $(>600 \mathrm{~nm})$ and blue-green light (460-540 nm). In both cases Cinemoid filters (Strand Electric, London, UK) were used to adjust the light quality.

Flies 1-3 d old at the beginning of an experiment were subjected first to $12 \mathrm{hr}$ light/dark (LD) cycles of spectral light with an irradiance that entrained most flies. After $\sim 10 \mathrm{~d}$ the irradiance was reduced to $10 \%$; simultaneously, the LD cycle was advanced by $6 \mathrm{hr}$. Flies that reentrained within $7 \mathrm{~d}$ were judged as entrainable at this particular irradiance and wavelength. The criteria for entrainment were a constant phase relationship of the flies' main activity peak (the evening peak) to the LD cycle and a period of $24 \mathrm{hr}$ [judged by periodogram analysis as described by Helfrich-Förster (1998)]. The phase relationship of the flies' evening peak to "lights-on" was determined after the data were smoothed with a nonrecursive digital low-pass filter that was applied over 101 data points at a cutoff frequency of $6 \mathrm{hr}$ (detailed description in HelfrichFörster, 2000). The evening peaks of an individual fly were defined as having a constant phase relationship to lights-on if the peak maxima occurred at the same time $( \pm 30 \mathrm{~min})$ on all consecutive days during a given LD cycle. Furthermore, the phase relation of the peak maxima to lights-on had to be similar ( $\pm 1 \mathrm{hr}$ ) before and after the advance of the LD cycle. When most flies $(>50 \%)$ within one recording unit reentrained within $7 \mathrm{~d}$, the irradiance was reduced again to $10 \%$, and the LD cycle was advanced by $6 \mathrm{hr} 10-15 \mathrm{~d}$ later. However, when $\geq 50 \%$ of the flies needed $\geq 7 \mathrm{~d}$ to reach their original phase relationship after the phase advance, the flies were judged to be at the limit of entrainment. Then the flies were kept at the same irradiance, but the LD cycle nevertheless was advanced to judge more accurately their capability to re-entrain. They were classified as re-entrained if they followed both phase advances at this particular irradiance within $7 \mathrm{~d}$. Experiments were done at least twice; in total, 11-43 flies of each genotype were tested for each irradiance and wavelength. The percentage of (re)entrained flies was determined and plotted against the irradiance (in photons $\cdot \mathrm{cm}^{-2} \cdot \mathrm{sec}^{-1}$ ) to derive dose-response curves for each wavelength. Action spectra were derived from these dose-response curves by determining the light intensities that were necessary to entrain $30,40,50$, 60,70 , and $80 \%$ of the flies, respectively. Because the dose-response curves were mainly parallel, we obtained similar action spectra at the different percentages of entrainment. Thus we chose the $60 \%$ values for determining the action spectra.

To compare the activity pattern of entrained mutant and wild-type flies at different wavelengths, we calculated average activity profiles as described previously (Helfrich-Förster, 2000). We did so at intermediate irradiances at which $\sim 70 \%$ of the flies entrained.

Statistics. The values of the evening peak maxima were distributed normally as revealed by the Lillefors test. They were analyzed with a one-way ANOVA for a significant influence of the wavelength on the time of peak. Values were regarded as significantly different at $p<0.05$ and as highly significantly different at $p<0.001$. A $\chi^{2}$ analysis (Zar, 1984) was used to reveal whether the presence of the morning peak was dependent on the genotype and on wavelength.

\section{RESULTS}

\section{Bolwig's organ transforms into eyelet during metamorphosis}

In larvae, the Bolwig's nerve projects from the larval photoreceptors toward the larval optic neuropil (for review, see Meinertzhagen and Hanson, 1993) over the face of the forming medulla (Fig. $1 A$ ). A difficulty in tracing a possible developmental relationship between it and eyelet is that expression of photoreceptor antigens turns off in Bolwig's organ during early pupal life, making it difficult to examine the possibility that Bolwig's organ might persist thereafter. Indeed, Bolwig's nerve was stained only faintly at $20 \%$ of pupal development $(\mathrm{P}+20 \%)$ (Fig. $1 B)$ and not at all in later stages (Fig. $1 C-F$ ). This was true not only for the expression of the GFP under the control of the strong photoreceptorspecific glass multiple reporter construct ( $g m r-G A L 4 ; U A S$-gfp line) (Fig. 1C) but also for photoreceptor-specific antibody staining with 24B10 (Zipursky et al., 1984) (Fig. 2B). We therefore examined the reporter line BS23 (Kr-BO-lacZ; Schmucker et al., 1992) driven by a promoter of the developmental gap gene Krüppel. This drives lac Z expression that is specific to Bolwig's organ (Schmucker et al., 1992), and the resultant immunoreactivity to $\beta$-gal indeed labeled Bolwig's organ and nerve from $\mathrm{P}+0 \%$ until eclosion (Fig. 3). In the white prepupa intense immunofluorescent labeling highlighted bilateral clusters of 12 cells lying near the larval mouthhooks and the axon bundles emerging from these (Fig. 3A). Profiles 5-6 $\mu \mathrm{m}$ in diameter detected in Bolwig's organ were probably photoreceptor nuclei (Fig. $3 A$, inset). In prepupal control preparations the labeling was seen neither in Bolwig's organ nor in Bolwig's nerve (data not shown).

During pupal development the cluster of cells in Bolwig's organ lost its rosette shape. Starting as soon as $\mathrm{P}+1 \mathrm{hr}$, labeled somata occupied progressively more caudal positions, as if the photoreceptors either were migrating caudally or were being retracted along the original pathway of their axons (Fig. 3B, C, inset). By $\mathrm{P}+5 \%$ the somata were split into two clusters retracting along this former path (Fig. 3C, inset) and were no longer adjacent to the mouthhooks. The number of cells in each cluster was not consistent (data not shown). At P $+10 \%$ the development of the retina in the eye disc and the formation of the optic neuropils were both apparent (data not shown), contributing additional axons to the pathway taken by Bolwig's nerve through the optic stalk between eye disc and brain (Steller et al., 1987). Bolwig's organ still contained $\sim 12$ cells but now comprised two quite distinct clusters like those seen at $\mathrm{P}+5 \%$. By $\mathrm{P}+20 \%$ (Fig. $3 B$ ) immunofluorescence labeled only three to six cells; however, the position of Bolwig's organ and nerve relative to the developing compound eye now anticipated that of eyelet. Then Bolwig's organ was detected below the expanding retina in an area that subsequently would become the posterior margin of the com- 
Figure 1. Bolwig's nerve and the eyelet tract both have a close spatial relationship to the lateral neurons in the developing optic lobe. Shown are confocal images of the right optic lobe in frontal view. Green channel, Photoreceptors (gmr-driven expression of GFP in $A-F$; antibody 24B10 in $G-I$ ); red channel, lateral neurons (antiPDH). Some ommatidia of the developing retina are visible in $D$ and $E$; other images depict the terminals of photoreceptors R1-R6 in the lamina $(L a)$ and R7, R8 in the second neuropil, the medulla $(M e)$. In larvae $(A)$ and $\mathrm{P}+20 \%$ pupae $(B)$, Bolwig's nerve $(B N)$ traverses the medulla and terminates directly in the larval optic neuropil (arrowhead), which transforms into the accessory medulla during metamorphosis. In the larval optic neuropil the terminals overlap putative dendrites from the small and large lateral neurons $\left(\mathrm{s}-\mathrm{LN}_{\mathrm{v}}\right.$ and $1-\mathrm{LN}_{\mathrm{v}}$ ). Additional fibers parallel to Bolwig's nerve (small green arrows) are possibly neurites of tangential neurons. Expression in the latter persists in early pupae $(B)$ when expression in Bolwig's nerve starts to disappear $(C)$. At approximately $\mathrm{P}$ $+50 \%(D)$ faint labeling first appears in the eyelet tract $(E y-T r)$ together with the first labeling in $1-\mathrm{LN}_{\mathrm{v}}$. At $\mathrm{P}+80 \%(E)$ the labeling pattern mainly resembles that of adult flies $(F)$. The tract from eyelet now shows a ventral extension overlapping arborizations of the 1- $\mathrm{LN}_{\mathrm{v}}$ (arrowheads). Fibers arising from $1-\mathrm{LN}_{\mathrm{v}}$ form a network over the surface of the medulla in close vicinity to the tract from eyelet (arrow in $F)$. Bolwig's tract $(G)$ and eyelet $(H)$ are present in eyeless sine oculis $\left(s O^{T}\right)$ mutants contacting the $\mathrm{LN}_{\mathrm{v}}$. $s o^{1}$ flies with tiny eye remnants possess, in addition, a well established axonal connection of their ommatidial photoreceptors to the medulla $(I)$. Scale bar: (in $I$ ) $A-I, 20 \mu \mathrm{m}$.

Figure 2. Bolwig's organ and the developing projection of eyelet. $A$, Frontal $8 \mu \mathrm{m}$ wax section of anterior region of third instar larva showing immunoreactivity to Rhodopsin 6 in Bolwig's organ $(B O)$, situated dorsally to the cephalopharyngeal skeleton (arrowheads). Differential interference contrast microscopy was used. $B, C$, Horizontal cryostat sections $10 \mu \mathrm{m}$ thick of pupal optic lobe immunolabeled with antibody 24B10. B, Pupa at approximately P + $45 \%$. In early pupal stages the developing medulla $(\mathrm{Me})$ lies orthogonal to the lamina $(L a)$, and the photoreceptor terminals of eyelet are not seen. $C$, Pupa at approximately $\mathrm{P}+70 \%$. At approximately $\mathrm{P}+$ $50 \%$ the medulla rotates, becoming concentric with the lamina, and the terminals of eyelet immunolabel at a position anterior to the medulla neuropil (arrow) corresponding to the accessory medulla. $R$, Retina. Cell bodies are not easily seen in this preparation. In the late pupa and adult the axons from the cells of eyelet project through the outer chiasm, and their terminals in the accessory medulla all label with photoreceptor-specific antibodies. Scale bars: $A, 10 \mu \mathrm{m}$; (in $B) B, C, 50 \mu \mathrm{m}$.

pound eye. At this stage the terminals of Bolwig's nerve were metamorphic, sometimes extending beyond the anterior medulla and occasionally $(n=2$ of $>50)$ so that their neurites met symmetrically at the midline (data not shown).

From $\mathrm{P}+20 \%$ on Bolwig's organ and nerve maintained their positions while the compound eye and optic neuropils formed around them (Fig. 3C,D). There was some defasciculation of Bolwig's nerve as it crossed the chiasma between lamina and medulla. At $\mathrm{P}+80 \%$ Bolwig's organ and nerve corresponded to eyelet and its tract when viewed in a horizontal plane (Fig. 3D). In newly eclosed BS23 flies Bolwig's organ, now transformed into eyelet, was still immunoreactive to $\beta$-gal, but the axons of 

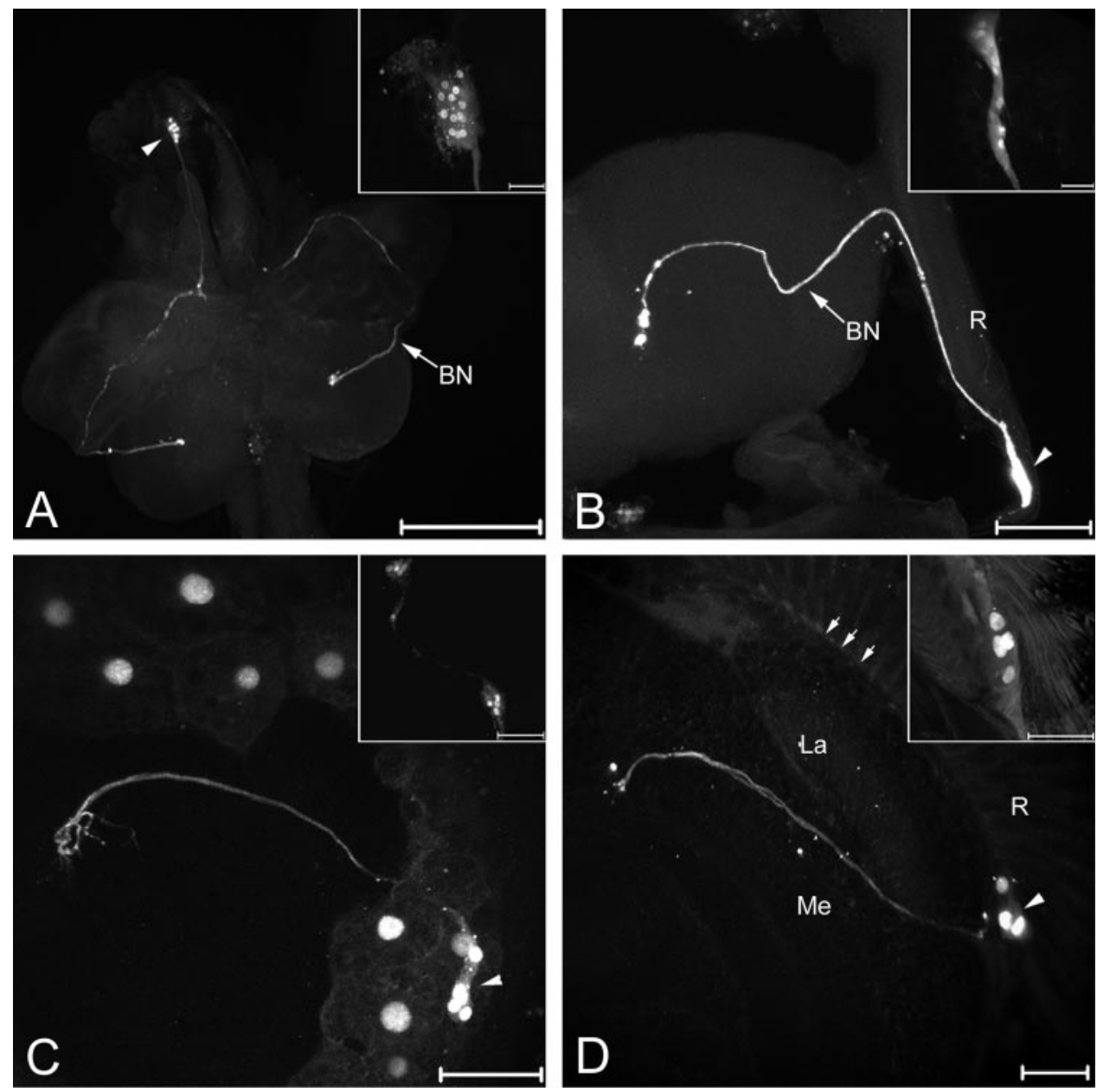

Figure 3. Krüppel-driven lacZ expression in Bolwig's organ and nerve persists throughout metamorphosis. Bolwig's organ and nerve throughout pupal metamorphosis are detected by immunoreactivity to $\beta$-gal in the transgenic line BS23 $(\mathrm{Kr}-\mathrm{BO}$ lac $Z$ ) in which lac $Z$ expression is driven by the promoter for Krüppel. A, Dorsal view of both eye discs and hemispheres in a wholemount preparation revealing Bolwig's organ (arrowhead) and the trajectory of its nerve $(B N)$ in the white prepupa. $B-D$, Horizontal Vibratome slices $(100 \mu \mathrm{m})$ of the right hemisphere of the pupal optic lobe at different stages: $B, \mathrm{P}+20 \% ; C, \mathrm{P}+$ $40 \% ; D, \mathrm{P}+80 \%$. Persistent $\beta$-gal expression reveals that Bolwig's organ is transformed into eyelet, the axon bundle of which is shown relative to the lamina ( $L a)$ and medulla $(M e$ ) neuropils (in $D)$, retina ( $R$ in $B, D$ ), and basement membrane (arrows in $D$ ). Cell number in Bolwig's organ decreases from 12 (inset, $A$ ) to four in the adult (inset, $D$ ) after separation from the mouthhooks at $\mathrm{P}+1 \mathrm{hr}$ (inset, $B$ ) and retraction of the cell bodies that are distributed in a trail of two clusters by $\mathrm{P}+5 \%$ (inset, $C$ ). Scale bars: $A, 250 \mu \mathrm{m} ; B, C$, inset in $C, 50 \mu \mathrm{m} ; D$, insets in $A$ and $B, 25 \mu \mathrm{m}$; inset in $D, 20 \mu \mathrm{m}$.
Bolwig's nerve were no longer as strongly labeled and in some cases were not detected (data not shown).

\section{Bolwig's organ and eyelet both express Rh6 immunoreactivity}

Bolwig's organ is reported to express immunoreactivity to three of six Drosophila rhodopsins that have been tested so far, Rh1, Rh3, and Rh4 (Pollock and Benzer, 1988), whereas eyelet expresses Rh6 (Yasuyama and Meinertzhagen, 1999). To examine whether this difference indicates a change in rhodopsin expression, we therefore examined immunoreactivity to Rh6 in Bolwig's organ. Clear expression of immunoreactivity to Rh6 was seen (Fig. 2A) in preparations made identically to those revealing Rh6 expression in eyelet (data not shown). Thus eyelet retains the expression found in Bolwig's organ.

\section{Bolwig's nerve and projection of eyelet both enjoy a close association with lateral neurons}

In the larval brain the circadian pacemaker center appears to consist of five small ventral lateral neurons (s- $\mathrm{LN}_{\mathrm{v}}$; Kaneko et al., 1997; Blanchardon et al., 2001). Four of these contain the neuropeptide PDF, a homolog of the crustacean neuropeptide PDH (Park and Hall, 1998). Arborizations of the PDF-expressing s- $\mathrm{LN}_{\mathrm{v}}$ visualized with an antibody against crab PDH (HelfrichFörster, 1997) innervate the larval brain hemispheres and have fine dendrite-like arborizations in the larval optic neuropil. There they overlap the terminals from Bolwig's nerve (Fig. 1A) (Kaneko et al., 1997).
In the pupa the medulla rotated from an anterior position (Fig. $2 B$ ) to a position between the lobula complex, lying beneath it, and the lamina (Fig. 2C) (Hofbauer and Campos-Ortega, 1990). It reached its final position by approximately $\mathrm{P}+50 \%$ at a time when faint GFP expression reappeared in a tract describing the same path toward the s- $\mathrm{LN}_{\mathrm{v}}$ as the former Bolwig's nerve (Fig. $1 D)$. This tract was traced during subsequent pupal development and corresponded to the projection of eyelet. At the same time, somata of the large $\mathrm{LN}_{\mathrm{v}}\left(1-\mathrm{LN}_{\mathrm{v}}\right)$ and their neurites first became immunoreactive to anti-PDH (Fig. 1D). As revealed in Figure $1 D$, these extended neurites into the accessory medulla, which originates from the larval optic neuropil (Ehnbohm, 1948; Hagberg, 1986; Helfrich-Förster, 1997). Whereas the larval optic neuropil was oval in shape, however, the accessory medulla formed a ventral elongation containing fibers arising from the l-LN $\mathrm{v}_{\mathrm{v}}$ (Fig. 1E,F) (cf. Helfrich-Förster, 1997). The eyelet tract followed this ventral elongation to form a ventral hook (Fig. $1 F$ ). At $\mathrm{P}+80 \%$ the immunolabeling of $\mathrm{LN}_{\mathrm{v}}$ cells and the eyelet tract were both very intense, closely resembling the adult pattern. In all brains that were investigated $(n=12)$ the terminals of the eyelet tract completely overlapped the $\mathrm{LN}_{\mathrm{v}}$ fibers in the accessory medulla. Furthermore, in $\sim 50 \%$ of the brains the eyelet tract lay in close vicinity to fibers from the $1-\mathrm{LN}_{\mathrm{v}}$ cells arborizing on the surface of the medulla (Fig. $1 F$ ). The spatial relationship between the eyelet tract and $\mathrm{LN}_{\mathrm{v}}$ fibers strongly suggests their functional connection and suggests that eyelet serves to transfer photic information toward the circadian pacemaker cells. A similar 
Figure 4. Ultrastructural differentiation of eyelet. Shown are the photoreceptors of eyelet at different stages of differentiation in pupal $(A)$ and adult $(B)$ flies. $A$, Pupa with amber eyes corresponding to approximately $\mathrm{P}+60 \%$ (Bainbridges and Bownes, 1981). The first microvilli of developing rhabdomeres have become distinct, but no pigment is yet visible. $B$, Fully differentiated eyelet photoreceptors with rhabdomeres and black pigment granules. $A r$ rows show developing microvillar structures in $A$ and fully developed rhabdomeres in $B$. Scale bar, $1 \mu \mathrm{m}$.
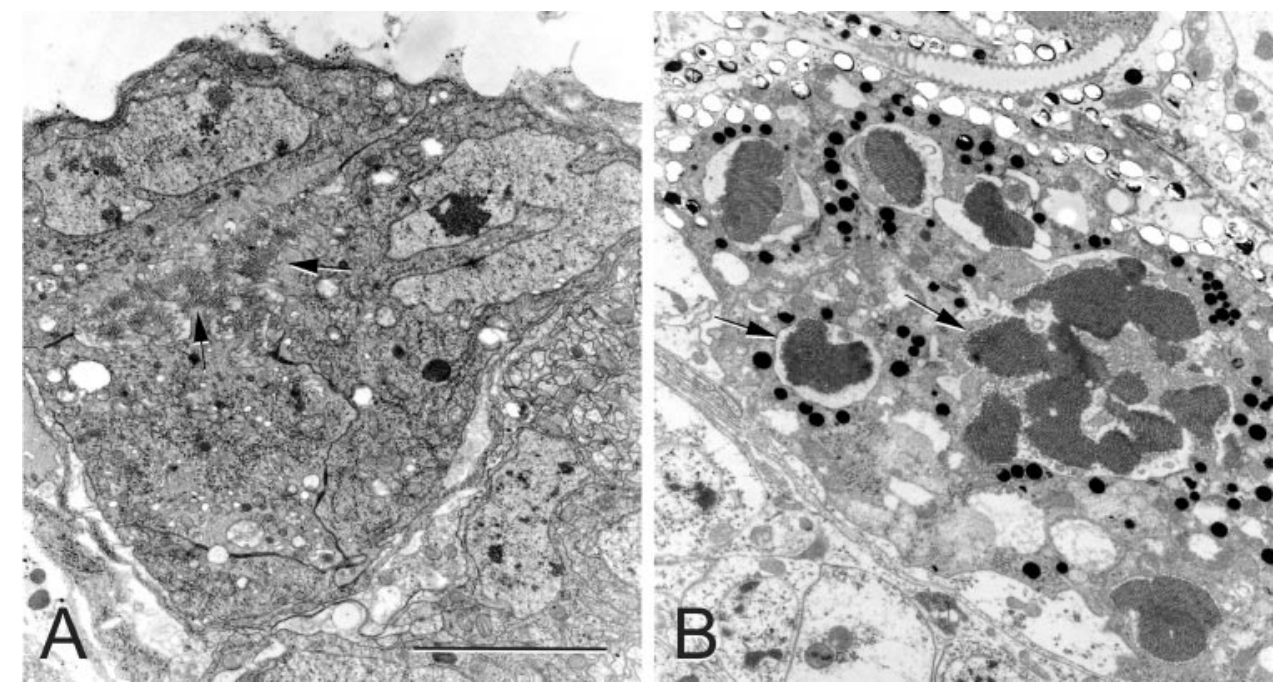

functional connection also may exist between photoreceptor cells R7 and R8 of the compound eyes, the axonal terminals of which are in close vicinity to the varicose network of the 1- $\mathrm{LN}_{\mathrm{v}}$ cells on the surface of the medulla (Fig. 1F).

\section{Ultrastructural differentiation of the eyelet cells commences in midpupal stages}

In adults eyelet contains between three and six neurons (Robinow and White, 1991), but usually four, all of which have an ultrastructure typical for photoreceptor cells (Yasuyama and Meinertzhagen, 1999). The four cells first were identified at approximately $\mathrm{P}+60 \%$ when rhabdomeric structures were first visible (Fig. 4A). At earlier stages we were not able to recognize the cells morphologically. At this stage of differentiation the beginning of rhabdomere formation is indicated by microvillar structures protruding into an intercellular space formed by the eyelet cells. This shows that the elaborate rhabdomeres as well as the pigmentation typical of the cells of the adult eyelet (Fig. $4 B$ ) are formed in the second half of pupal development, comparable in time course to that for the retinal photoreceptor cells of the compound eye. The time course of this differentiation indicates that the larval photoreceptor cells dedifferentiate in early metamorphosis and then redifferentiate to attain their imaginal structure.

\section{Eyelet is present in eyeless sine oculis ${ }^{1}$ flies but is absent in the double-mutant sine oculis ${ }^{1}$; glass $^{60 j}$}

Compatible with the formation of eyelet from Bolwig's organ, eyeless flies $\left(s o^{1}\right)$ have a normal Bolwig's organ (Cheyette et al., 1994) and have been shown previously to retain eyelet (Hofbauer and Buchner, 1989). As in wild-type flies, Bolwig's nerve and the eyelet tract both are associated closely with the $\mathrm{LN}_{\mathrm{v}}$ cells (Fig. $1 G, H)$. By comparison, mutant glass $\left(\mathrm{gl}^{60 j}\right)$ flies lack Bolwig's organ (Kunes et al., 1993) and eyelet (Helfrich-Förster et al., 2001). To reveal whether eyelet plays an active role in circadian entrainment, we therefore could compare the light sensitivity of the circadian system between flies that retained and flies that lacked eyelet but that were otherwise similar. To do this, we generated double-mutant $s o^{1} ; g l^{60 j}$ flies that were identical in the shielding properties of their head with $s o^{1}$ flies (see Materials and Methods). Whole-mount preparations and cryostat sections of mutant $s O^{1}$ and $s O^{1} ; g l^{60 j}$ flies then were checked for the presence of eyelet by using the photoreceptor-specific antibody 24B10 that reliably marks this structure and, in the case of $s o^{1}$, additionally checked with anti-TAU in flies expressing TAU under control of the Rh6 promotor. Eyelet and its tract were clear in most $s o^{1}$ flies (31 of 34 brain hemispheres labeled with 24B10 and 24 of 27 hemispheres with anti-TAU). In $s o^{1} ; g l^{60 j}$ mutants eyelet was absent. In only one brain hemisphere of 60 was a 24B10immunoreactive structure found that resembled eyelet in size, but this was neither at its normal location nor did its axons project to the $\mathrm{LN}_{\mathrm{v}}$; we therefore concluded that this structure did not represent eyelet.

\section{Action spectra in mutant flies}

To study the function of eyelet in detail, we determined action spectra for entraining the activity rhythm of adult $s O^{1}$ and $s O^{1} ; g l^{60 j}$ flies. An action spectrum plots the magnitude of a photobiological response as a function of the wavelength of light eliciting the response. Ideally, the action spectrum matches the absorption spectrum of the photoactive pigment. To test the hypothesis that eyelet provides a photic input to entrain the fly's activity rhythm, we quantified entrainment from the percentage of entrained flies at different irradiances and wavelengths (see Materials and Methods). To ensure that flies entrained to the LD cycles and simply did not free-run with a period of $24 \mathrm{hr}$, we subjected them to a 6 hr phase advance of the LD cycle (Fig. 5); only flies that shifted their activity rhythm within $7 \mathrm{~d}$ were judged to be entrained. First we determined dose-response curves between irradiance and the percentages of resynchronized flies for each wavelength (Fig. $6 A$ ). The slopes of the semilog curves for different wavelengths were essentially equal. Action spectra were derived from the intersection of the curves with the $60 \%$ synchronization value (Fig. 6B). For $s O^{1}$ flies the action spectrum showed two peaks, at 420 and $\sim 480 \mathrm{~nm}$. The action spectrum for $s o^{1} ; g l^{60 j}$ flies was similar to the $s O^{1}$ spectrum at wavelengths shorter than $450 \mathrm{~nm}$, but the peak at $480 \mathrm{~nm}$ was virtually absent. Wavelengths longer than $550 \mathrm{~nm}$ failed to synchronize both mutants. This differed from wild-type flies (Fig. $6 B$; derived from data in Blaschke et al., 1996) that, like the mutants, showed two peaks in their action spectrum but that were $\sim 100$ times more sensitive and showed considerable sensitivity in the red part of the spectrum. In summary, these results suggest that the compound eyes contribute to entrainment over a broad spectral range extending into the red, whereas cryptochrome is responsible for the sensitivity peak at $\sim 420 \mathrm{~nm}$ and eyelet is responsible for that at $480 \mathrm{~nm}$. If true, then 


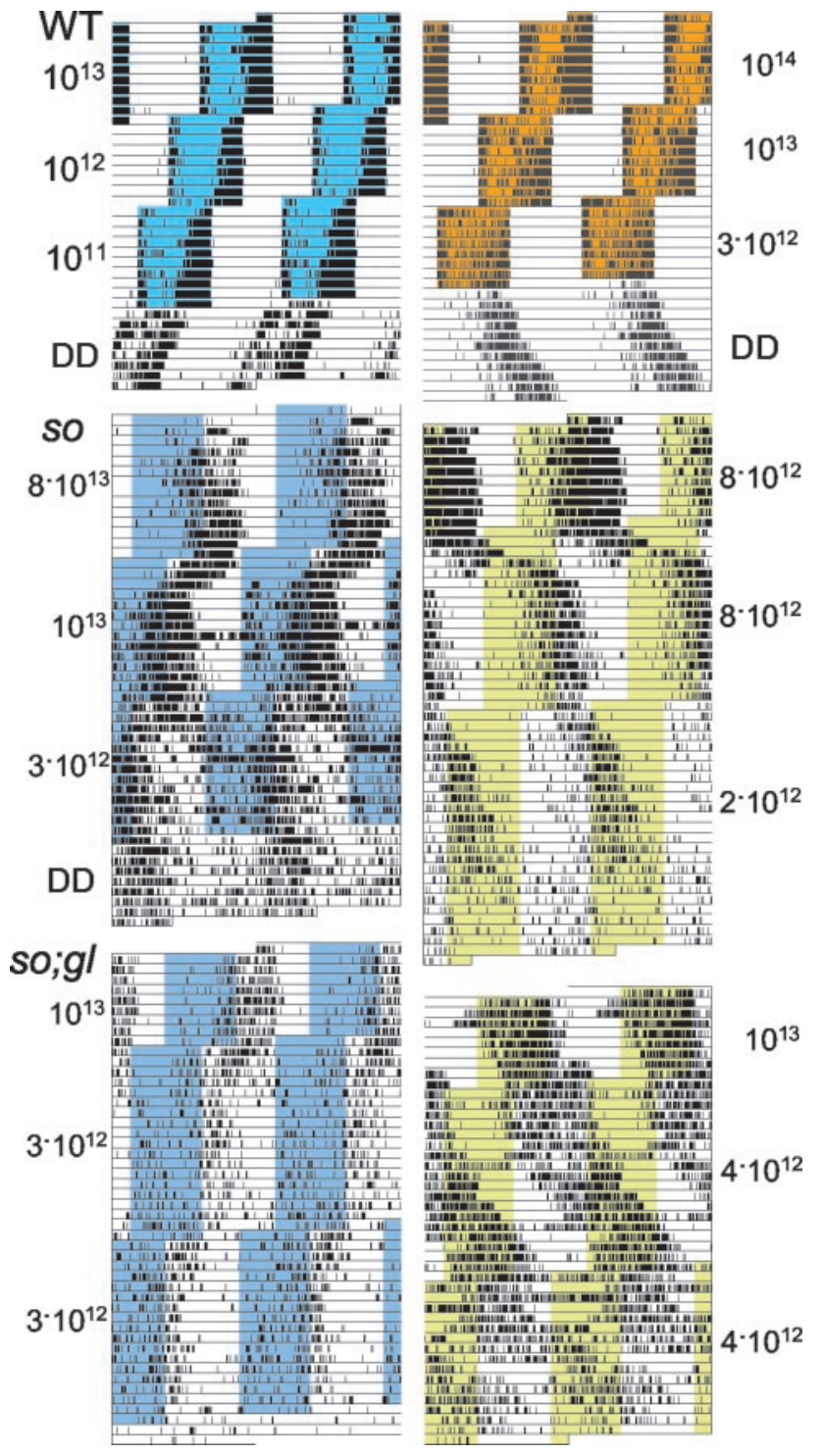

Figure 5. Entrainment of flies by spectral light. Shown are representative actograms from wild-type flies $(W T), s o^{1}$ flies, and $s o^{1} ; g l^{60 j}$ flies subjected to $12 \mathrm{hr}$ light/dark cycles (LD) of different wavelengths, the phase of which was advanced twice by $6 \mathrm{hr}$. One-half of the flies subsequently were recorded under constant darkness $(D D)$. Light was blue-green (top left panel, 460-540 $\mathrm{nm}$ ), red (top right panel, >600 nm), blue (middle and bottom left panels, $420 \mathrm{~nm}$ ), or green (middle and bottom right panels, 486 $\mathrm{nm})$. Irradiances are indicated in the margin in photons $\cdot \mathrm{cm}^{-2} \cdot \mathrm{sec}^{-1}$. Wild-type flies re-entrained quickly to the $6 \mathrm{hr}$ phase advances, showing bimodal activity patterns with morning and evening peaks. Activity was restricted mainly to the light phase of the LD cycle. Mutants extended activity into the dark phase and needed several days to re-entrain to phase advances. Some flies failed to re-entrain to green light $\left(s o^{1} ; g b^{60 j}\right.$ and $s o^{1}$ after second phase advance). The morning peak was visible in $s o^{l}$ flies only during the blue LD cycle after the first phase shift and faintly during the green LD cycle before the first phase shift. The $s o^{1}$ fly in green light showed antidromic phase shifting.

mutants that retain only eyelet but lack compound eyes and cryptochrome should maintain the sole peak at $480 \mathrm{~nm}$. To test this hypothesis, we generated $s o^{1} ; c r y^{b}$ double mutants and tested their entrainability at different wavelengths. To judge the contribution of the compound eyes, we also tested $\mathrm{so}^{1} ;$ cry $^{b}$ flies that possessed tiny remnants of the compound eyes containing between 10 and 50 ommatidia. Histologically, such flies showed well
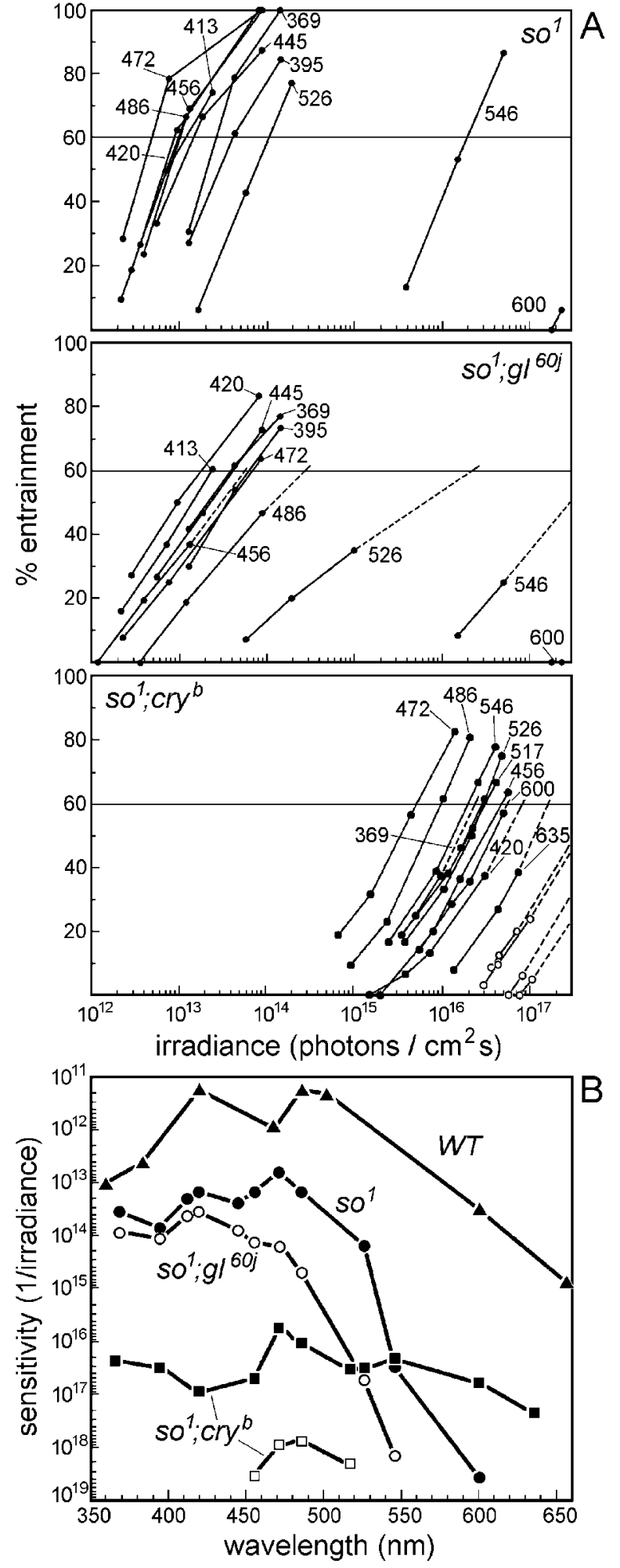

Figure 6. Dose-response curves for re-entrainment and corresponding action spectra. The dose-response curves $(A)$ for $s O^{I}, s O^{I} ; g l^{60 j}$, and $s O^{I}$; $c r y^{b}$ flies show the percentage of re-entrained flies for all wavelengths as a function of the irradiance. For $s o^{I} ; c r y^{b}$ mutants both the flies with eye remnants $(\bullet)$ and completely eyeless flies $(\bigcirc)$ were tested. From left to right, the wavelengths for eyeless flies were 472, 486, 517, and $456 \mathrm{~nm}$. Action spectra $(B)$ were derived from these dose-response curves by determining the light intensities that were necessary to entrain $60 \%$ of the flies at each wavelength. The action spectrum for wild-type flies is derived from data by Blaschke et al. (1996). 
established axonal connections of their few ommatidial photoreceptors to a small underlying lamina and to the medulla, which was enlarged at the site of photoreceptor innervation (Fig. 1I).

As expected, the sensitivity peak at $420 \mathrm{~nm}$ was lacking in $s O^{1}$; $c r y^{b}$ flies, whereas that at $\sim 480 \mathrm{~nm}$ remained (Fig. $6 B$ ). This shows unequivocally that the $420 \mathrm{~nm}$ peak in the action spectrum derives from cryptochrome and indicates that the $480 \mathrm{~nm}$ peak stems from eyelet. However, only very few eyeless $s o^{1}$; $c r y^{b}$ flies at all were able to follow the $6 \mathrm{hr}$ phase advance of the LD cycle. At $456 \mathrm{~nm}$ one of 20 flies (5\%), at $471 \mathrm{~nm}$ three of 31 flies (9.7\%), at $486 \mathrm{~nm}$ three of 24 flies $(12.5 \%)$, and at $517 \mathrm{~nm}$ one of 16 $(6.3 \%)$ flies re-entrained. At the other wavelengths we did not find any re-entrainment in eyeless $s o^{1}$; $c r y^{b}$ flies, not even at the highest irradiance possible with our light source $\left(10^{17}\right.$ photons $\left.\cdot \mathrm{cm}^{-2} \cdot \mathrm{sec}^{-1}\right)$. Although the few cases of entrained flies occurred at the putative sensitivity maximum of eyelet, eyelet alone thus appears not to be capable of reliably entraining the activity rhythm. Rather, the additional presence of either cryptochrome or the compound eyes may be required. As soon as only a few ommatidia were present in $s O^{1}$; $c r y^{b}$ flies, the $480 \mathrm{~nm}$ sensitivity peak became more prominent and the sensitivity of the circadian system extended from the blue into the red, but the sensitivity peak at $420 \mathrm{~nm}$ was absent (Fig. 6B). This shows clearly that the compound eyes contribute to the flies' sensitivity throughout the spectrum and are especially responsible for that at longer wavelengths. Probably because of the small number of ommatidia present, however, the overall sensitivity of $\mathrm{so}^{1} ;$ cry $^{b}$ flies with eye remnants was considerably less than that of wildtype flies (Fig. 6B).

\section{The pattern of activity in eyeless mutants}

Wild-type flies showed a bimodal activity pattern, with a morning peak at approximately lights-on, an evening peak at approximately lights-off, and little activity during the dark phase even at the higher and medium irradiance levels of the wavelengths that were tested (e.g., $10^{11}-10^{13}$ photons $\cdot \mathrm{cm}^{-2} \cdot \mathrm{sec}^{-1}$ of blue-green light) (Fig. 7). However, under spectral light of low intensities (e.g., at $10^{10}$ photons $\cdot \mathrm{cm}^{-2} \cdot \mathrm{sec}^{-1}$ blue-green light) at the limits of entrainment, wild-type flies frequently lacked the morning peak (I. Blaschke, unpublished observations). Eyeless flies ( $s o^{I}$ and $s O^{1} ; g l^{60 j}$ mutants) already lacked the morning peak at rather high irradiances (Fig. 5). At the highest irradiances that were applied here (e.g., $10^{14}$ photons $\cdot \mathrm{cm}^{-2} \cdot \mathrm{sec}^{-1}$ of blue-green light), only $50 \%$ of the $s o^{1}$ mutants and $55 \%$ of the $s o^{1} ; g l^{60 j}$ mutants still had a normal bimodal activity pattern with morning and evening peaks, whereas at intermediate irradiances (e.g., $2 \times 10^{13}$ photons $\cdot \mathrm{cm}^{-2} \cdot \mathrm{sec}^{-1}$ blue-green light) only $25 \%$ of the $s o^{1}$ and $24 \%$ of the $s o^{1} ; g l^{60 j}$ mutants were bimodal; at the lowest irradiances that still led to entrainment $\left(3 \times 10^{12}\right.$ photons $\cdot \mathrm{cm}^{-2} \cdot \mathrm{sec}^{-1}$ blue green light) all flies were unimodal, lacking the morning peak completely. This behavior was independent of the wavelength in both mutants $\left(\chi_{(9,182 / 119)}^{2}<8.95 ; p>0.442\right)$, and no significant differences in the presence of the morning peak were found between the two mutants $\left(\chi_{(1,301)}^{2}=0.54 ; p=0.461\right)$.

Whereas the maximum for the evening peak was $\sim 2 \mathrm{hr}$ before lights-off in wild-type flies and in $s o^{1} ; c r y^{b}$ flies with eye remnants, it occurred after lights-off in the eyeless flies (Fig. 7). Such an activity phase lag is expected for animals having a free-running period of $>24 \mathrm{hr}$ (Moore-Ede et al., 1982). Indeed, both groups of eyeless flies had periods of at least $24.6 \mathrm{hr}(24.61 \pm 0.07 \mathrm{hr}$ for $s O^{1} ; g l^{60 j}$ and $24.72 \pm 0.07 \mathrm{hr}$ for $s O^{1}$ ) under constant darkness (DD) conditions, whereas the average period for wild-type and

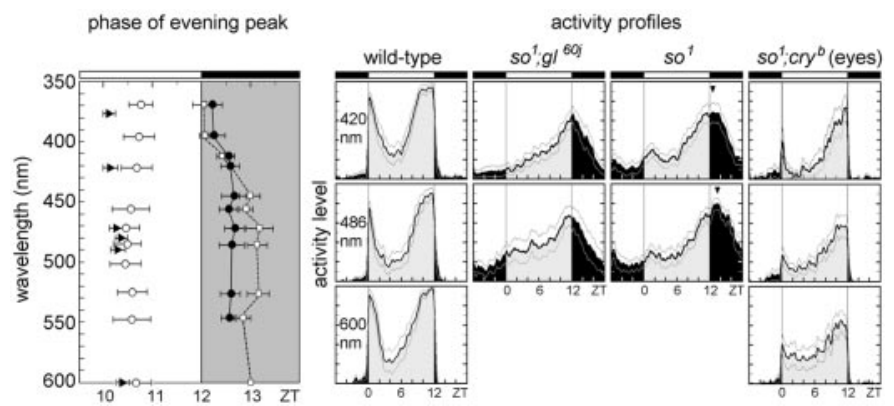

Figure 7. Phase plot of evening activity peaks and average activity profiles of entrained flies at different wavelengths. The black and white bars along the top of each plot indicate the light/dark regimen. The maxima of the evening peaks occurred before lights-off in wild-type flies $(\boldsymbol{\Delta})$ and in $s O^{1} ;$ cry $^{b}$ mutants with eye remnants $(O)$ but after lights-off in both $s o^{1} ; g l^{60 j}(\mathbf{O})$ and $s o^{1}(\square)$ mutants. Average activity profiles at wavelengths of 420,486 , and $600 \mathrm{~nm}$ reveal that the activity of wild-type flies and $s o^{1} ; c r y^{b}$ mutants with eye remnants is restricted mainly to the light phase of the LD cycle, whereas it extends into the dark phase in the eyeless mutants $s o^{1}$ and $s o^{I} ; g^{60 j}$ (black portion of the curves). In $s o^{I}$ mutants the phase of the evening peak was dependent on the wavelength and occurred later at longer wavelengths (see phase plot and arrows in the activity profiles of $s o^{1}$ flies). Except for a single fly, the eyeless $s o^{1}$ and $s o^{1} ; g l^{60 j}$ were not entrainable at $600 \mathrm{~nm}$, so average activity profiles could not be calculated for these flies at that wavelength. ZT, Zeitgeber time $(\mathrm{ZT} 0=$ lights-on; ZT 12 = lights-off).

$s o^{1}$; $c r y^{b}$ flies was close to $24.0 \mathrm{hr}$. Interestingly, the phase relationship of the evening peak to the LD cycle was dependent on the wavelength in $s o^{1}$ mutants (ANOVA, $F_{(9,142)}=4.74 ; p<$ 0.001): the longer the wavelength, the larger the phase lag (Fig. 7). We did not see such a dependency in $5 O^{1} ; g^{60 j}$ mutants nor in $s o^{1}$; $c r y^{b}$ flies with compound eye remnants nor in wild-type flies $\left(\mathrm{ANOVA}, F_{(9,63)}=0.72 ; p=0.675\right)$.

\section{Flies with or without eyelet differ in the pattern of their resynchronization}

Of the two ways to resynchronize to a $6 \mathrm{hr}$ phase advance of the LD cycle, the most likely is simply for the clock to follow the shift in the LD cycle and advance its phase by $6 \mathrm{hr}$ (orthodromic phase shifting). However, it is also possible to delay the phase by $18 \mathrm{hr}$ (antidromic phase shifting). Although most $s o^{1} ; g^{60 j}$ flies phase advanced their clock, as expected, many $s o^{1}$ flies reacted unexpectedly and phase-delayed their clock (Fig. 5, Table 1). Interestingly, the antidromic phase shifting of $s o^{1}$ depended on the wavelength, occurring predominantly at longer wavelengths close to the putative sensitivity maximum of eyelet as inferred from our results $(480 \mathrm{~nm})$. In contrast, the few cases of antidromic phase shifting in $s o^{1} ; g l^{60 j}$ flies occurred at $\sim 420 \mathrm{~nm}$ (Table 1). Wild-type flies tested in a parallel experiment for their capability to entrain in the red $(n=19)$ or blue-green $(n=14)$ all advanced their clock after a 6 hr phase advance (Fig. 5). Similarly, all $s o^{1} ; c r y^{b}$ flies with eye remnants phase advanced their clock. The aberrant behavior of $s o^{1}$ flies corresponds to the phase lag of the evening peak observed in $s O^{1}$ mutants at longer wavelengths and could result from either a very long period or an altered phase-response curve in $s o^{1}$ flies. Because $s o^{1}$ and $s o^{1} ; g l^{60 j}$ flies had the same long period, however, they should react similarly, yet this was obviously not the case. We therefore propose that eyelet mainly mediates phase delays but that this property becomes evident only in the absence of the compound eyes. 
Table 1. Percentages of antidromic phase shifting at different wavelengths in sine oculis ${ }^{1}$ and sine oculis $^{1}$; glass $^{60 j}$ mutants

\begin{tabular}{|c|c|c|c|c|c|c|}
\hline $\mathrm{nm}$ & $n$ & $s o^{1}$ antidromic & Percentage & $n$ & $s o^{1} ; g l^{60 j}$ antidromic & Percentage \\
\hline 369 & 14 & 1 & 7.1 & 10 & 0 & 0 \\
\hline 395 & 11 & 3 & 27.3 & 12 & 0 & 0 \\
\hline 412.5 & 26 & 5 & 19.2 & 26 & 1 & 3.9 \\
\hline 420 & 21 & 4 & 19.1 & 15 & 4 & 26.7 \\
\hline 445 & 17 & 7 & 41.2 & 15 & 2 & 13.3 \\
\hline 456 & 25 & 12 & 44.0 & 14 & 1 & 7.1 \\
\hline 472 & 17 & 12 & 70.6 & 10 & 1 & 10.0 \\
\hline 486 & 21 & 15 & 71.4 & 10 & 0 & 0 \\
\hline 526 & 16 & 14 & 87.5 & 4 & 0 & 0 \\
\hline 546 & 13 & 10 & 76.9 & 3 & 0 & 0 \\
\hline 600 & 1 & 1 & $(100)$ & 0 & 0 & 0 \\
\hline
\end{tabular}

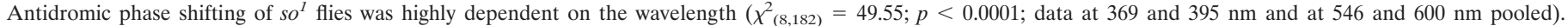
Furthermore, $s o^{I}$ flies overall showed significantly more antidromic phase shifting than $s o^{1}$; $g l^{60 j}$ flies $\left(\chi_{(1,301)}^{2}=50.19 ; p<0.0001\right.$; data for all wavelengths pooled).

\section{DISCUSSION}

The aims of the present study were to investigate the anatomical relationship of eyelet to both the antecedent Bolwig's organ and the fly's pacemaker or lateral neurons to examine the differentiation of eyelet and, from its action spectrum, to evaluate its involvement in circadian entrainment.

\section{The origin of eyelet from Bolwig's organ}

To examine these questions, we first needed to determine whether eyelet is a remnant of the larval Bolwig's organ or whether it develops anew. Our observations on the Krüppel reporter line clearly support the first hypothesis. Although the photoreceptors of Bolwig's organ differ from those of eyelet (Yasuyama and Meinertzhagen, 1999) in number (Steller et al., 1987), position, and ultrastructure (Melzer and Paulus, 1989; Paulus, 1989), our observations reveal that eyelet photoreceptors stem from the 12 larval photoreceptors, the surviving four members of which retract to occupy the position of eyelet in the adult. This explains why the eyelet tract coincides so precisely with the previous pathway of Bolwig's nerve. During their retraction in the young pupa the photoreceptors of Bolwig's organ lose downstream photoreceptor-specific expression such as immunoreactivity to 24B10, which they regain later in pupal life with the differentiation of the photoreceptors of eyelet. Coexpression of immunoreactivity to two fast neurotransmitter systems, histamine and acetylcholine, already has been reported in eyelet (Yasuyama and Meinertzhagen, 1999). This rather perplexing finding thus could be reconciled as persistent immunoreactivity to ChAT, retained from Bolwig's organ (Yasuyama et al., 1995) overlapping the expression of histamine immunoreactivity newly arisen in eyelet. Expression of Rh6 either is retained from Bolwig's organ or is reestablished in the photoreceptors of eyelet.

The finding that only approximately four of the original 12 cells from Bolwig's organ survive pupation may reflect their embryonic origin from approximately four atonal and rhomboid (rho)positive founder cells (Daniel et al., 1999; Suzuki and Saigo, 2000). Via rho activity these four also express Spitz, which then signals neighboring cells to activate Spitz transcription and in turn become Bolwig's organ cells. Spitz expression then maintains the fate of all 12 cells (Daniel et al., 1999). Possibly in the young pupa Spitz is silenced in Bolwig's organ, with the loss of the laterally specified cells and a reversion in the structure of Bolwig's organ to the original four founder cells.

\section{The spatiotemporal association between photoreceptors of eyelet and circadian pacemaker neurons}

As described previously (Kaneko et al., 1997), we found that terminals of Bolwig's nerve overlap the putative dendritic field of the $\mathrm{s}-\mathrm{LN}_{\mathrm{v}}$. This relationship is not simply anatomical because, together with the blue-light photoreceptor cryptochrome, the larval photoreceptors also mediate entrainment of the molecular oscillations of the pacemaker (Kaneko et al., 2000). The circadian function of Bolwig's organ in the larva apparently is resumed in the adult fly, by eyelet, which likewise mediates entrainment, apparently together with cryptochrome and, now, the compound eyes. The anatomical data presented here are consistent with such a role. The photoreceptors of eyelet differentiate concurrently with the l-LN $\mathrm{N}_{\mathrm{v}}$, and the neurites of both cell types maintain a close spatial relationship to each other during pupal morphogenesis. They overlap partially on the surface of the medulla and completely in the accessory medulla. Although the eyelet tract arises from Bolwig's nerve, it differs from the latter in one important detail, namely the ventral elongation of the terminal of the eyelet nerve, which follows the fibers of the $1-\mathrm{LN}_{\mathrm{v}}$ in the accessory medulla. In the latter, the axon terminals of eyelet also overlap with putative dendrites of the $\mathrm{s}-\mathrm{LN}_{\mathrm{v}}$ that are the most important in controlling adult behavioral rhythmicity (for review, see Kaneko, 1998; Edery, 2000) (see also Emery et al., 2000b). These anatomical credentials qualify eyelet to transfer photic information to the fly's circadian clock.

Action spectra imply a role for the compound eyes, for cryptochrome, and for eyelet in circadian entrainment

Wild-type flies have major sensitivity peaks at 420 and $500 \mathrm{~nm}$. The peak at $420 \mathrm{~nm}$ obviously is caused by the blue-light photopigment cryptochrome and that at $500 \mathrm{~nm}$ by the compound eyes and eyelet combined (see below). In addition to their action spectrum, wild-type flies are simply more sensitive than $s O^{1}$ or $s o^{1}$; $g l^{60 j}$ flies by $\sim 10^{2}$ times between 360 and $550 \mathrm{~nm}$ and by $10^{3}$ to $10^{4}$ times at wavelengths $>550 \mathrm{~nm}$. Thus the compound eyes provide a strong input to entrainment of the circadian clock, especially at longer wavelengths. Accordingly, $s o^{1} ; c r y^{b}$ flies with tiny eye remnants are entrainable by wavelengths $>550 \mathrm{~nm}$, whereas their eyeless siblings are not. The compound eye photopigment conferring sensitivity to long wavelengths could be Rh6, which expresses in a subgroup of the R8 photoreceptors of the ommatidia and has an absorption maximum $\left(\lambda_{\max }\right)$ at $530 \mathrm{~nm}$ 
(Salcedo et al., 1999). This sensitivity also could derive from Rhodopsin $1\left(\mathrm{Rh} 1 ; \lambda_{\max }=486 \mathrm{~nm}\right)$, which is expressed in photoreceptors R1-R6 of the ommatidia. Rh1 has a metarhodop$\sin$ that is sensitive in the red $\left(\lambda_{\max }=566 \mathrm{~nm}\right)$. At illumination the rhodopsins are photoconverted into metarhodopsins that then photoreisomerize back into rhodopsins (Hamdorf, 1979). The physiologically derived spectral sensitivity of R1-R6 should reflect the mixed absorption of both rhodopsin forms and therefore extend into the red, as in the action spectra for wild-type flies and $s o^{1} ; c r y^{b}$ mutants with eye remnants. Anatomically, the compound eyes may provide direct light input to the l- $\mathrm{LN}_{\mathrm{v}}$ via photoreceptors R7 and R8, the terminals of which are in close vicinity to the fiber network of the l- $\mathrm{LN}_{\mathrm{v}}$ on the surface of the medulla. This is true for wild-type flies as well for $s O^{1}$ mutants with eye remnants.

In addition to the compound eyes, the action spectra clearly confirm cryptochrome as a circadian photopigment that is still active in flies lacking both compound eyes and eyelet (Emery et al., 1998, 2000a,b; Stanewsky et al., 1998; Helfrich-Förster et al., 2001). The sensitivity peak at $420 \mathrm{~nm}$ in $s o^{1} ; g l^{60 j}$ flies that retain cryptochrome as the sole circadian photoreceptor coincides nicely with the absorption peak of cryptochrome (Selby and Sancar, 1999). Furthermore, flies lacking cryptochrome $\left(\mathrm{so}^{1} ;\right.$ cry $^{b}$ mutants) lack the sensitivity peak at $420 \mathrm{~nm}$.

The fact that the ultrastructural reorganization of eyelet is not complete until eclosion already suggests that eyelet assumes a function only in adult flies and may serve as a third photoreceptor of the circadian system. Our determinations of the action spectra of circadian entrainment support this view. As in wild-type flies, $s o^{1}$ flies have two sensitivity peaks in their action spectrum, at 420 and $480 \mathrm{~nm}$. In contrast, the action spectrum of $s o^{1} ; g l^{60 j}$ flies virtually lacks the $480 \mathrm{~nm}$ peak, suggesting that this peak stems from eyelet. Like the earlier Bolwig's organ (see Results), eyelet is immunoreactive to Rh6 (Yasuyama and Meinertzhagen, 1999), which has $\lambda_{\max }$ at $530 \mathrm{~nm}$ and a metarhodopsin $\lambda_{\max }$ at $468 \mathrm{~nm}$ (Salcedo et al., 1999). Furthermore, some eyelet photoreceptor cells may express Rh5 (Malpel et al., 2002) with $\lambda_{\max }$ at $442 \mathrm{~nm}$ and a metarhodopsin $\lambda_{\max }$ at $500 \mathrm{~nm}$. If all eyelet photoreceptor inputs carry equal weight, the physiologically derived spectral sensitivity should reflect the mixed absorption of all four rhodopsin forms and lie at $\sim 480 \mathrm{~nm}$, exactly as observed in the action spectrum of $s o^{1}$ flies. Consistent with this, flies with only eyelet show entrainment solely at $\sim 480 \mathrm{~nm}$. Conviction on this point is frustrated only because so few flies actually entrain at this wavelength, indicating that, acting alone, eyelet is a rather weak photoreceptor of the circadian system. We cannot exclude, however, that this weak influence is attributable to less extensively developed eyelet terminals in the mutant $s o^{1}$ compared with the wild type (compare Fig. 1H,I).

Our action spectra clearly speak for an active role of eyelet in circadian entrainment, but we have to consider possible side effects of the glass mutation on central brain neurons, which also might cause spectral sensitivity differences between $s O^{1}$ and $s O^{1}$; $\mathrm{gl}^{60 j}$ flies. This is because, besides photoreceptor cells, glass also expresses in a few central brain neurons (Moses and Rubin, 1991; Ellis et al., 1993; Vosshall and Young, 1995) that the $\mathrm{gl}^{60 j}$ mutation therefore may eliminate. Indeed, we found recently that a subgroup of the period gene expressing dorsal neurons (DN1) is missing in $g l^{60 j}$ mutants (Helfrich-Förster et al., 2001). Like the $\mathrm{H}-\mathrm{B}$ eyelets, these dorsal neurons send axonal projections toward the $\mathrm{LN}_{\mathrm{v}}$ (Kaneko and Hall, 2000) through which they theoretically could entrain the latter. Furthermore, flies bearing a mutation in the disconnected (disco) gene, which mainly lack the $\mathrm{LN}_{\mathrm{v}}$ but not the DN1 cells, are able to entrain to LD cycles (Zerr et al., 1990; Hardin et al., 1992; Helfrich-Förster, 1998). The DN1 are present in $s o^{1}$ mutants (Kaneko, 2000; B. Wisotzky and A. Hofbauer, unpublished observations) and therefore could account for differences in the action spectra of $s o^{1}$ and $s o ; g l^{60 j}$ flies. However, it is not known whether the DN1 cells express rhodopsins at all and, if so, whether the $\lambda_{\text {max }}$ of such DN1 rhodopsins fits the action spectrum as do Rh5 and Rh6 in eyelet.

\section{Eyelet appears to play a complex role in the circadian system of flies}

Although we cannot exclude a role for the DN1 cells as circadian photoreceptors, the anatomical and action spectrum data presented here support a role for eyelet in the entrainment pathway of $D$. melanogaster. Several observations indicate that this putative role is complex, however.

Obviously, eyelet functions only in concert with cryptochrome (in $s o^{1}$ flies) or with the compound eyes (in $s o^{1} ; c r y^{b}$ flies with eye remnants). Depending on which additional photoreceptor is present, eyelet seems to have quite different effects on the activity rhythm.

In the presence of cryptochrome but without the compound eyes eyelet appears to mediate phase delays. The evening peak of $s o^{1}$ flies is phase delayed, and $s o^{1}$ flies frequently show antidromic phase shifting. Interestingly, both phase delaying effects occur only at wavelengths close to the putative $\lambda_{\max }$ of eyelet, implicating eyelet as the source of these behaviors. Nevertheless, in the presence of tiny eye remnants but in the absence of cryptochrome no phase lag of the evening peak is observed, and the flies show no antidromic phase shifting.

In summary, our results indicate that eyelet is a pupal transformation of Bolwig's organ, that both receptor systems have an association with the PDH-immunoreactive lateral neurons, and that both mediate circadian entrainment exhibiting an action spectrum, which for eyelet in the adult fly is based in part on Rh6 expression possibly also inherited from the photoreceptors of Bolwig's organ in the larva. Apparently, cryptochrome and rhodopsins of eyelet and the compound eyes collude in a complex manner to entrain the adult fruit fly's circadian activity to the 24 hr day. This dual nature of circadian photoreception encompassing opsins and cryptochromes as photopigments resembles the situation in mammals in which melanopsin and cryptochromes of the inner retina apparently team up with rhodopsin in the rods to entrain the circadian system of mice (Freedman et al., 1999; Selby et al., 2000; Lucas et al., 2001; Thompson et al., 2001; Berson et al., 2002; Hattar et al., 2002).

\section{REFERENCES}

Adler K (1976) Extraocular photoreception in amphibians. Photochem Photobiol 23:275-298.

Bainbridges SP, Bownes M (1981) Staging the metamorphosis of Drosophila melanogaster. J Embryol Exp Morphol 66:57-80.

Bennett MF (1979) Extraocular light receptors and circadian rhythms. In: Handbook of sensory physiology, Vol VII/6A (Autrum H, ed), pp 641-663. Berlin: Springer.

Berson DM, Dunn FA, Takao M (2002) Phototransduction by retinal ganglion cells that set the circadian clock. Science 295:1070-1073.

Blanchardon E, Grima B, Klarsfeld A, Chélot E, Hardin PE, Préat T, Rouyer F (2001) Defining the role of Drosophila lateral neurons in the control of circadian activity and eclosion rhythms by targeted genetic ablation and PERIOD protein overexpression. Eur J Neurosci 13:871-888.

Blaschke I, Lang P, Hofbauer A, Engelmann W, Helfrich-Förster C (1996) Preliminary action spectra suggest that the clock cells of Drosophila are synchronized to the external LD cycle by the compound eyes plus extraretinal photoreceptors. In: Brain and evolution. Proceed- 
ings of the 24th Göttingen neurobiology conference, Vol I (Elsner N, Schnitzler H-U, eds). Stuttgart: Thieme.

Bolwig N (1946) Senses and sense organs of the anterior end of the house fly larvae. Vidensk Medd Dansk naturh Forenh Kbh 109:81-217.

Brand AH, Perrimon N (1993) Targeted gene expression as a means of altering cell fates and generating dominant phenotypes. Development 118:401-415.

Callahan CA, Thomas JB (1994) Tau- $\beta$-galactosidase, an axon-targeted fusion protein. Proc Natl Acad Sci USA 91:5972-5976.

Cheyette BNR, Green PJ, Martin K, Garren H, Hartenstein V, Zipursky SL (1994) The Drosophila sine oculis locus encodes a homeodomaincontaining protein required for the development of the entire visual system. Neuron 12:977-996.

Daniel A, Dumstrei K, Lengyel JA, Hartenstein V (1999) The control of cell fate in the embryonic visual system by atonal, tailless, and EGFR signaling. Development 126:2945-2954.

Dircksen H, Zahnow CA, Gaus G, Keller R, Rao KR, Riehm JP (1987) The ultrastructure of nerve endings containing pigment-dispersing hormone (PDH) in crustacean sinus glands: identification by an antiserum against a synthetic PDH. Cell Tissue Res 250:377-387.

Edery I (2000) Circadian rhythms in a nutshell. Physiol Genomics 3:59-74.

Ehnbohm K (1948) Studies on the central and sympathetic nervous system and some sense organs in the head of neuropteroid insects. Opus Entomol Suppl 8:1-162.

Ellis MC, O’Neill EM, Rubin GM (1993) Expression of Drosophila glass protein and evidence for negative regulation of its activity in nonneuronal cells by another DNA-binding protein. Development 119:855-865.

Emery P, So WV, Kaneko M, Hall JC, Rosbash M (1998) CRY, a Drosophila clock and light-regulated cryptochrome, is a major contributor to circadian rhythm resetting and photosensitivity. Cell 95:669-679.

Emery P, Stanewsky R, Hall JC, Rosbash M (2000a) A unique circadian rhythm photoreceptor. Nature 404:456-457

Emery P, Stanewsky R, Helfrich-Förster C, Emery-Le M, Hall JC, Rosbash M (2000b) Drosophila CRY is a deep-brain circadian photoreceptor. Neuron 26:493-504.

Felisberti F, Ventura DF, Hertel H (1997) Cerebral extraocular photoreceptors in beetles. Comp Biochem Physiol [A] Physiol 118:1353-1357.

Fischbach K-F, Technau G (1984) Cell degeneration in the developing optic lobes of the sine oculis and small-optic-lobes mutants of Drosophila melanogaster. Dev Biol 104:219-239.

Fleissner G, Fleissner G, Frisch B (1993) A new type of putative nonvisual photoreceptors in the optic lobe of beetles. Cell Tissue Res 273:435-445.

Frank KD, Zimmermann WF (1969) Action spectra for phase shifts of a circadian rhythm in Drosophila. Science 163:688-689.

Freedman MS, Lucas RJ, Soni B, von Schantz M, Muñoz M, David-Gray Z, Foster R (1999) Regulation of mammalian circadian behavior by non-rod, non-cone, ocular photoreceptors. Science 284:502-504.

Freeman M (1996) Reiterative use of the EGF receptor triggers differentiation of all cell types in the Drosophila eye. Cell 87:651-660.

Gibbs SM, Truman JW (1998) Nitric oxide and cyclic GMP regulate retinal patterning in the optic lobe of Drosophila. Neuron 20:83-93.

Hagberg M (1986) Ultrastructure and central projections of extraocular photoreceptors in caddiesflies (Insecta: Trichoptera). Cell Tissue Res 245:643-648

Hamdorf K (1979) The physiology of invertebrate visual pigments. In: Handbook of sensory physiology, Vol VII/6A (Autrum H, ed), pp 145-224. Berlin: Springer.

Hardin PE, Hall JC, Rosbash M (1992) Behavioral and molecular analyses suggest that circadian output is disrupted by disconnected mutants in D. melanogaster. EMBO J 11:1-6.

Hattar S, Liao H-W, Takao M, Berson DM, Yau K-W (2002) Melanopsin-containing retinal ganglion cells: architecture, projections, and intrinsic photosensitivity. Science 295:1065-1070.

Helfrich-Förster C (1997) Development of pigment-dispersing hormone immunoreactive neurons in the nervous system of Drosophila melanogaster. J Comp Neurol 380:335-354.

Helfrich-Förster C (1998) Robust circadian rhythmicity of Drosophila melanogaster requires the presence of lateral neurones: a brainbehavioral study of disconnected mutants. J Comp Physiol [A] 182:435-453.

Helfrich-Förster C (2000) Differential control of morning and evening components in the activity rhythm of Drosophila melanogaster-sexspecific differences suggest a different quality of activity. J Biol Rhythms 15:135-154.

Helfrich-Förster C, Stengl M, Homberg U (1998) Organization of the circadian system in insects. Chronobiol Int 15:567-594.

Helfrich-Förster C, Täuber M, Park JH, Mühlig-Versen M, Schneuwly S, Hofbauer A (2000) Ectopic expression of the neuropeptide pigmentdispersing factor alters behavioral rhythms in Drosophila melanogaster. J Neurosci 20:3339-3353.

Helfrich-Förster C, Winter C, Hofbauer A, Hall JC, Stanewsky R (2001)
The circadian clock of fruit flies is blind after elimination of all known photoreceptors. Neuron 30:249-261.

Hoch M, Schröder C, Seifert E, Jäckle H (1990) Cis-acting control elements for Krüppel expression in the Drosophila embryo. EMBO J 9:2587-2595.

Hofbauer A, Buchner E (1989) Does Drosophila have seven eyes? Naturwissenschaften 76:335-336.

Hofbauer A, Campos-Ortega JA (1990) Proliferation pattern and early differentiation of the optic lobes in Drosophila melanogaster. Roux's Arch Dev Biol 198:264-274.

Kaneko M (1998) Neural substrates of Drosophila rhythms revealed by mutants and molecular manipulations. Curr Opin Neurobiol 8:652-658.

Kaneko M (2000) Neural substrates of circadian rhythms in developing and adult Drosophila. PhD thesis, Brandeis University.

Kaneko M, Hall JC (2000) Neuroanatomy of cells expressing clock genes in Drosophila: transgenic manipulation of the period and timeless genes to mark the perikarya of circadian pacemaker neurons and their projections. J Comp Neurol 422:66-94.

Kaneko M, Helfrich-Förster C, Hall JC (1997) Spatial and temporal expression of the period and timeless genes in the developing nervous system of Drosophila: newly identified pacemaker candidates and novel features of clock gene product cycling. J Neurosci 17:6745-6760.

Kaneko M, Hamblen MJ, Hall JC (2000) Involvement of the period gene in developmental time-memory: effect of the per $^{\text {Short }}$ mutation on phase shifts induced by light pulses delivered to Drosophila larvae. J Biol Rhythms 15:13-30.

Klemm E, Ninnemann H (1976) Detailed action spectrum for the delay shift in pupae emergence of Drosophila pseudoobscura. Photochem Photobiol 24:369-371.

Kunes S, Wilson C, Steller H (1993) Independent guidance of retinal axons in the developing visual system of Drosophila. J Neurosci $13: 752-767$

Lindsley DL, Zimm GG (1992) The genome of Drosophila melanogaster. San Diego: Academic.

Lucas RJ, Freedman MS, Lupi D, Muñoz M, David-Gray ZK, Foster RG (2001) Identifying the photoreceptive inputs to the mammalian circadian system using transgenic and retinally degenerate mice. Behav Brain Res 125:97-102.

Malpel S, Klarsfeld A, Rouyer F (2002) Larval optic nerve and adult extra-retinal photoreceptors sequentially associate with clock neurons during Drosophila brain development. Development 129:1443-1453.

Meinertzhagen IA, Hanson TE (1993) The development of the optic lobe. In: The development of Drosophila melanogaster (Bate M, Arias AM, eds), pp 1363-1491. Cold Spring Harbor, N Y: Cold Spring Harbor Laboratory.

Meinertzhagen IA, Pyza E (1996) Daily rhythms in cells of the fly's optic lobe: taking time out from the circadian clock. Trends Neurosci 19:285-291

Melzer RR, Paulus HF (1989) Evolutionswege zu den Larvalaugen der Insekten-die Stemmata der höheren Dipteren und ihre Umbildung zum BOLW IG-Organ. Z Zool Syst Evolutions-forsch 27:200-245.

Moore-Ede MC, Sulzman FM, Fuller CS (1982) The clocks that time us. Physiology of the circadian timing system. Cambridge, MA: Harvard UP.

Morin LP (1994) The circadian visual system. Brain Res Brain Res Rev 19:102-127.

Moses K, Rubin GM (1991) Glass encodes a site-specific DNA-binding protein that is regulated in response to positional signals in the developing Drosophila eye. Genes Dev 5:583-593.

Moses K, Ellis MC, Rubin GM (1989) The glass gene encodes a zincfinger protein required by Drosophila photoreceptor cells. Nature 340:531-536.

Ohata K, Nishiyama H, Tsukahara Y (1998) Action spectrum of the circadian clock photoreceptor in Drosophila melanogaster. In: Biological clocks. Mechanisms and applications (Touitou Y, ed), pp 167-170. Amsterdam: Elsevier.

Page TL (1982) Extraretinal photoreception in entrainment and photoperiodism in invertebrates. Experientia 38:1007-1013.

Park JH, Hall JC (1998) Isolation and chronobiological analysis of a neuropeptide pigment-dispersing factor gene in Drosophila melanogaster. J Biol Rhythms 13:219-228.

Park JH, Helfrich-Förster C, Lee G, Liu L, Rosbash M, Hall CJ (2000) Differential regulation of circadian pacemaker output by separate clock genes in Drosophila. Proc Natl Acad Sci USA 97:3608-3613.

Paulus HF (1989) Das Homologisieren in der Feinstrukturforschung: Das Bolwig-Organ der höheren Dipteren und seine Homologisierung mit Stemmata und Ommatidien eines ursprünglichen Fazettenauges der Mandibulata. Zool Beitr NF 32:437-478.

Pollack I, Hofbauer A (1991) Histamine-like immunoreactivity in the visual system and brain of Drosophila melanogaster. Cell Tissue Res 266:391-398.

Pollock JA, Benzer S (1988) Transcript localization of four opsin genes in the three visual organs of Drosophila: RH2 is ocellus specific. Nature 333:779-782. 
Provencio I, Rollag MD, Castrucci AM (2002) Photoreceptive net in the mammalian retina. Nature 415:493.

Pyza E, Meinertzhagen IA (1997) Neurites of period-expressing PDH cells in the fly's optic lobe exhibit circadian oscillations in morphology. Eur J Neurosci 9:1784-1788.

Renn SCP, Park JH, Rosbash M, Hall JC, Taghert PH (1999) A pdf neuropeptide gene mutation and ablation of PDF neurons each cause severe abnormalities of behavioral circadian rhythms in Drosophila. Cell 99:791-802.

Roberts DB, ed (1998) Drosophila. A practical approach, 2nd Ed. Oxford, UK: IRL

Robinow S, White K (1991) Characterization and spatial distribution of the ELAV protein during Drosophila melanogaster development. J Neurobiol 22:443-461.

Salcedo E, Huber A, Henrich S, Chadwell LV, Chou W-H, Paulsen R, Britt SG (1999) Blue- and green-absorbing visual pigments of Drosophila: ectopic expression and physiological characterization of the R8 photoreceptor cell-specific Rh5 and Rh6 rhodopsins. J Neurosci 19:10716-10726.

Schmucker D, Taubert H, Jäckle H (1992) Formation of the Drosophila larval photoreceptor organ and its neuronal differentiation require continuous Krüppel gene activity. Neuron 9:1025-1039.

Schulz W-D, Schlüter U, Seifert G (1984) Extraocular photoreceptors in the brain of Epilachna varivestis (Coleoptera, Coccinellidae). Cell Tissue Res 236:317-320.

Seifert P, Smola U, Schinko I (1987) Internal extraocular photoreceptors in a dipteran insect. Tissue Cell 19:111-118.

Selby CP, Sancar A (1999) A third member of the photolyase/blue-light photoreceptor family in Drosophila: a putative circadian photoreceptor. Photochem Photobiol 69:105-107.

Selby CP, Thompson C, Schmitz TM, Van Gelder RN, Sancar A (2000) Functional redundancy of cryptochromes and classical photoreceptors for nonvisual ocular photoreception in mice. Proc Natl Acad Sci USA 97:14697-14702.

Stanewsky R, Kaneko M, Emery P, Beretta B, Wager-Smith K, Kay SA, Rosbash M, Hall JC (1998) The cry $^{b}$ mutation identifies cryptochrome as a circadian photoreceptor in Drosophila. Cell 95:681-692.

Steller H, Fischbach K-F, Rubin GM (1987) Disconnected: a locus re- quired for neuronal pathway formation in the visual system of Drosophila. Cell 50:1139-1153.

Suri V, Qian Z, Hall JC, Rosbash M (1998) Evidence that the TIM light response is relevant to light-induced phase shifts in Drosophila melanogaster. Neuron 21:225-234.

Suzuki T, Saigo K (2000) Transcriptional regulation of atonal required for Drosophila larval eye development by concerted action of eyes absent, sine oculis and hedgehog signaling independent of Fused kinase and Cubitus interruptus. Development 127:1531-1540.

Thompson CL, Blaner WS, Van Gelder RN, Lai K, Quadro L, Colantuoni V, Gottesman ME, Sancar A (2001) Preservation of light signaling to the suprachiasmatic nucleus in vitamin A-deficient mice. Proc Natl Acad Sci USA 98:11708-11713.

Tix S, Minden JS, Technau GM (1989) Pre-existing neuronal pathways in the developing optic lobes of Drosophila. Development 105:739-746.

Truman JW (1976) Extraretinal photoreception in insects. Photochem Photobiol 23:215-225.

Underwood H, Groos G (1982) Vertebrate circadian rhythms: retinal and extraretinal photoreception. Experientia 38:1013-1021.

Vosshall LB, Young MW (1995) Circadian rhythms in Drosophila can be driven by period expression in a restricted group of central brain cells. Neuron 15:345-360.

Yang Z, Emerson M, Su HS, Sehgal A (1998) Response of the timeless protein to light correlates with behavioral entrainment and suggests a nonvisual pathway for circadian photoreception. Neuron 21:215-223.

Yasuyama K, Meinertzhagen IA (1999) Extraretinal photoreceptors at the compound eye's posterior margin in Drosophila melanogaster. J Comp Neurol 412:193-202.

Yasuyama K, Kitamoto T, Salvaterra PM (1995) Localization of choline acetyltransferase-expressing neurons in the larval visual system of Drosophila melanogaster. Cell Tissue Res 282:193-202.

Zar JH (1984) Biostatistical analysis. Englewood Cliffs, NJ: Prentice Hall.

Zerr DM, Hall JC, Rosbash M, Siwicki KK (1990) Circadian fluctuations of period protein immunoreactivity in the CNS and the visual system of Drosophila. J Neurosci 10:2749-2762.

Zipursky SL, Venkatesh TR, Teplow DB, Benzer S (1984) Neuronal development in the Drosophila retina: monoclonal antibodies as molecular probes. Cell 36:15-26. 